\title{
Glial Cell Colony Injured on Exposure to Fullerene Soot Nanoparticles
}

\author{
Athira Sairanthry Suku ${ }^{1,+\infty}$, Ashtami Jayakumar $1,+(\mathbb{D}$, Mohanan Parayanthala Valappil $1, *,+(\mathbb{D})$ \\ 1 Toxicology Division, Biomedical Technology WingSree Chitra Thirunal Institute for Medical Sciences and Technology \\ (Govt. of India), Trivandrum 695 012, Kerala, India \\ * Correspondence: mohanpv10@gmail.com; \\ $\dagger$ Equal contribution
}

Scopus Author ID 7006010446

Received: 9.07.2020; Revised: 12.08.2020; Accepted: 15.08.2020; Published: 19.08.2020

\begin{abstract}
An expansion in the field of nanotechnology and their applications in medicine and pharmaceuticals have revolutionized the $20^{\text {th }}$ century. Principally it deals with particles exhibiting a size below $100 \mathrm{~nm}$ at least in a single dimension. Various fields that gain application potentials of nanotechnology include health and medicine, electronics, energy and environment, space research, etc. Advancements in experimental techniques have to lead to the development of multi functionalized nanoparticles like fullerenes, which is one of the allotropic forms of carbon. Fullerene was initially fabricated by laser ablation of graphite in an inert atmosphere. The crude early form consists of a mixture of interlocked carbon cages in its impure version, referred to as fullerene soot. Nature gets exposed to fullerene soot from a cluster of sources, including vehicle, industrial, and other household exhausts. An increasing level of exposure requires toxicity evaluation of such materials in biological systems. Present study addresses in vitro toxicity studies of fullerene soot nanoparticles in C6 glial cells. The study particularly analyzes cell viability assays, morphological evaluations, organelle functionality analysis, live-dead assays, and nuclear integrity measurement. The study confirms the dose-dependent toxicity of the nanomaterials, which further recommends proper precautions to be taken during exposure occasions.
\end{abstract}

Keywords: fullerene soot; nanoparticles; glial cells; toxicity; biomedical.

(C) 2020 by the authors. This article is an open-access article distributed under the terms and conditions of the Creative Commons Attribution (CC BY) license (https://creativecommons.org/licenses/by/4.0/).

\section{Introduction}

Nanotechnology principally deals with engineering or fine-tuning of functional matters at their molecular level. The field has generated exciting scientific attention globally because of the innumerable possibilities it holds. Since it offers opportunities to mold and exploit structures below 100 nanometers, there exist tremendous amounts of application potentials $[1,2]$. Nanotechnology has witnessed climb in its path by the emergence of a lot many sophisticated techniques including scanning tunneling microscope, magnetic force microscope, electron microscopes, etc. This allows researchers to observe and manipulate matter at its atomic level. Parallel advancement in the emergence of lithographic techniques in the field of electronic devices allowed researchers to effectively reduce the size of matter and cost of experiments [3,4]. Nanoscience and nanotechnology could be considered as two interdisciplinary branches of science, both of which are strongly bonded to each other. It was during the $10^{\text {th }}$ plan period (2002-2007), the Nanoscience and Technology Mission (NSTM) was put forward, which was later upgraded during succeeding $11^{\text {th }}$ plan (2007-2012), which 
included another initiative known as 'Nano mission'. This initiative, later on, caused India to be one of the top five nations around the world in contributing a great number of research and publications about nanoscience and technology [5,6]. Nanotechnology involves a broad range of tools and techniques which tenders huge level of applications in various scenarios like water purification devices, medical diagnosis, and therapies, energy sources, long-lasting building materials and utensils, food and agriculture, electronics, etc.

\section{Properties and applications}

The convergence of scanning the electron microscope (invented in 1981) and fullerene cages (1985) have brought greater advancements in nanotechnology during the late 1980s. Fullerenes are allotropes of carbon, which has been considered as a relatively novel category of molecules in nanotechnology family. Contrasting to other carbon allotropes like graphite and diamond, it has got certain unique characteristics, including hollow carbon cage structure and geometrical features [7,8]. Structurally fullerenes consist of round shaped organizations bearing a number of hexagons and pentagons bonded tightly together. In 1985, the first molecule of pure fullerene was invented by a panel of scientists, Richard Smalley, Robert Curl, James Heath, Sean O'Brien, and Harold Kroto at Rice University and they named it as Buckminster fullerene (C60) due to its resemblance with a Buckyball structure [9]. For this splendid discovery, the panel won Nobel Prize for Chemistry in 1996. The experimentation for this involved, vaporization of solid graphite using a laser source followed by chilling down using helium ions. Another simpler method of generation of fullerenes includes from fuel flame of certain hydrocarbons. This could bring large amounts of impure fullerene forms comprising C60 and C70 in an indefinite ratio. Reports are available on the context that this fullerene soot fine powder is capable of imposing scrotal cancer in chimney sweepers [10,11]. Toxic consequences of fullerene soot nanoparticles were also evident in lung epithelial cells [12].

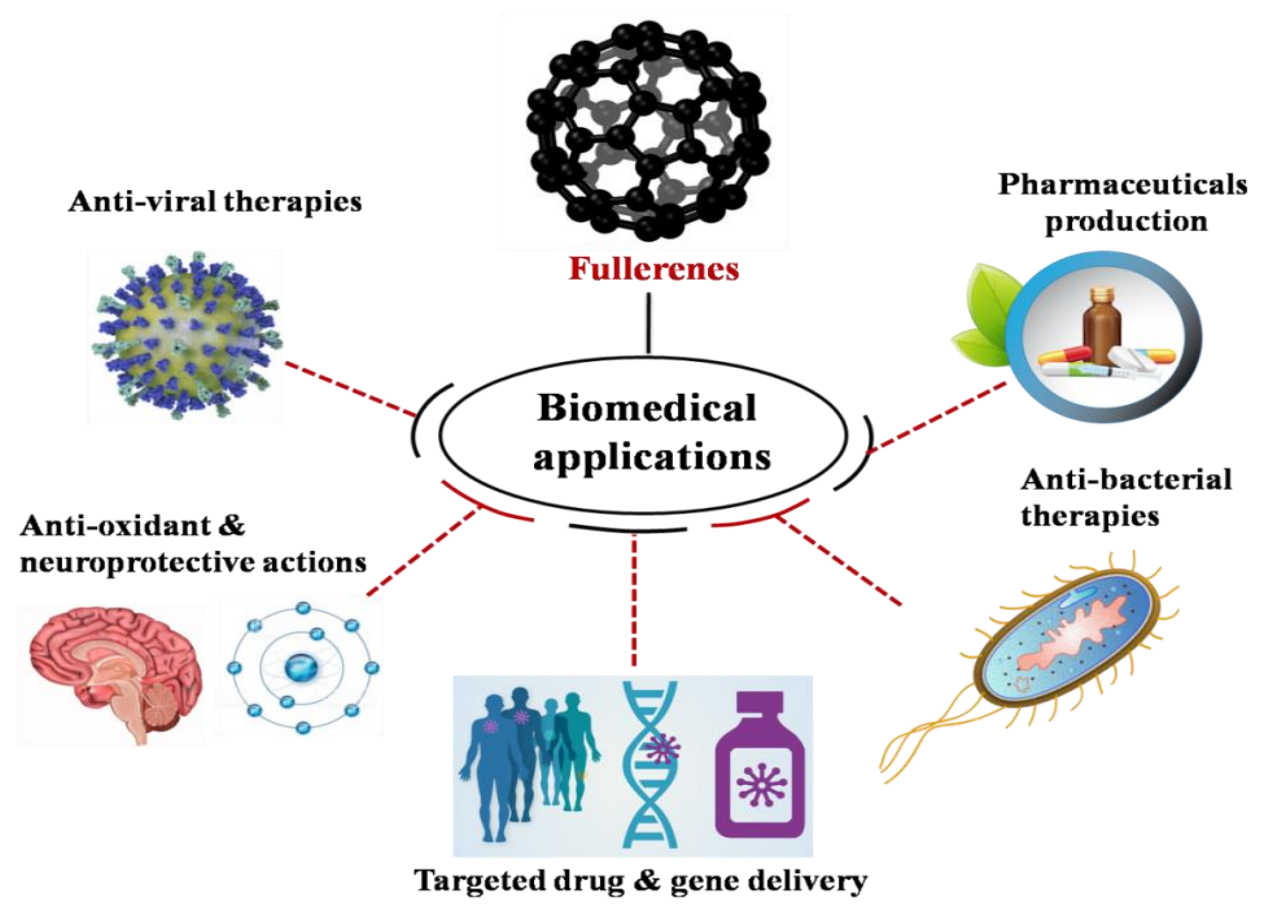

Figure 1. Bio-medical applications of fullerene. 
Direct applications of fullerenes and their derivatives have found promising applicability in various medicinal as well as industrial fields. Biomedical application (Figure 1) includes, in anti-viral therapies, antioxidant and neuroprotective therapies, targeted drug and gene therapies, theranostics, anti-microbial therapies, enzyme inhibition properties, pharmaceutical applications, etc.[13].

\section{Safety and toxicity}

Fullerene is reported to be able to cross the neuronal cell membranes and also exhibit neuroprotection against oxidative stress with its antioxidant effects. Carboxyfullerene, a watersoluble derivative of fullerene, showed scavenging activity against super-oxides and hydrogen peroxide radical. Importantly, carboxy fullerene exposure to familial amyotrophic lateral sclerosis induced mouse model caused a delay in motor failure and death. Carboxyfullerenes are stated to be reliable neuroprotective oxidants in neurodegenerative diseases, including Alzheimer's disease [14]. On the background of biomedical applications, various toxicity studies are being conducted for ensuring biocompatibility of fullerene derivatives. In a study by Ashtami et al. [2019], C60 fullerene was observed to be non-toxic in L929 fibroblastic cells [15]. The same group of authors later confirmed the safer applicability of fullerene C60 via in vitro toxicity studies using the $\mathrm{CHO}$ cell line [16]. Tykhomyrov et al. reported that the administration of a water-soluble derivative of fullerene on chronic alcoholized rat model protected the central nervous system of the treated animals from oxidative stress-induced injuries. Hydro-derivative fullerene exposure helped in averting the loss of astrocytes, usually associated with chronic alcoholization. Also, treatment with hydro-derivative of fullerene uptake also aided in overcoming behavioral impairment caused by high alcohol consumption. The free radical scavenging property of fullerene indeed helps in preventing radical-induced oxidative stress and associated toxicity. Such an observation was noted during the safety assessment of fullerene C60 using CHO cells by Biby et al. in 2019 [17]. However, on the contrary, ROS induced toxic response induced by similar material was observed in C6 glial cells [18]. Polyhydroxylated fullerene is reported to protect the hippocampus from peroxideinduced toxicity and thereby act as a neuroprotectant [19]. Such a wide range of applications of fullerenes and related compounds further necessitates their toxicity evaluations in model systems. The simultaneous existence of contrasting reports regarding fullerene toxicity in different in vitro and in vivo environments, adds an increased requirement of a deepened knowledge on the same.

In an interesting study, Yamago et al., intravenously injected ${ }^{14} \mathrm{C}$-labeled fullerene derivative that was water-soluble. The water-soluble derivative was found to be distributed throughout the body, and most of the administrated dose was found to be retained in various organs. The labeled fullerene derivative even crossed the blood-brain barrier and reached the brain. The intravenous injection did not elicit any toxic response, but intraperitoneal administration of the water-soluble labeled fullerene raised toxic response [20]. These may be because fullerene caused inflammatory reactions when high dose concentration is accumulated to a specific surface area just as in case of intraperitoneal injection. In intravenous administration, diffusion into the blood causing dilution in concentration helps overturn toxicity arising from accumulation [21]. The capability of fullerene to cross the blood-brain barrier calls for the need to assess the compatibility of fullerene soot nanoparticles with neurons. Industrial/ automobile exhaust, incomplete fuel decomposition, burning, etc., releases fullerene soot nanoparticles into the air. So, we are a high risk of exposure to fullerene soot 
nanoparticle through inhalation. Since the fullerene soot nanoparticles are having finite nanosize, they can easily reach alveoli from where they are translocated into the bloodstream and get distributed to different organs, including the brain. So, it is high time to consider the toxicity of fullerene soot particles on neuronal cells. The only limited literature review is available on the toxicity of fullerene soot nanoparticles on neuron cells. Notably, pristine fullerene, when exposed to C6 glioma and U251 human glioma cells, resulted in ROS intermediated necrosis. Cell membrane rupture was evident in treated cells depicting the fact that pristine fullerene caused cytotoxicity in neuronal cells. On the contrary, carboxy fullerenes showed delayed ROS generation when exposed to cells, and cell death was caused by apoptosis [22]. Similarly, Sayes et al. showed that nanofullerene when exposed to human astrocyte cells, caused disruption in normal cell function by lipid peroxidation, and cell membrane damage was also observed [23]. Contradictory reports on the potential use of fullerene for neuronal application as well on its toxicity makes it difficult to make a valid conclusion on this account.

The present review elaborates on an in vitro toxicity evaluation of fullerene soot nanoparticles in C6 glial cells. From the available literature suggesting limited hydrophilicity of fullerenes [24], an effective polymer functionalization was employed using dextran in a study by Athira et al. [11]. Followed by proper physicochemical characterization of the functionalized fullerene using different techniques, an array of in vitro assays was performed to analyze the level of neurotoxicity. Distinct peaks obtained for FT/IR analysis confirmed the effective functionalization of fullerene soot nanoparticles with dextran. Also, nanometer-size was found to be maintained even after functionalization as per transmission electron microscopic observation. Homogenous distribution and colloidal stability of the compound were also confirmed.

The initial cytotoxic response of fullerene soot nanoparticles was evaluated using MTT and Neutral Red Uptake assays using different concentrations of fullerene soot nanoparticles $(5,10,20,40$, and $160 \mu \mathrm{g} / \mathrm{ml})$ prepared in DMEM. Both the assays suggested a dose and timedependent toxicity in which a statistically significant observation was observed from $40 \mu \mathrm{g} / \mathrm{ml}$ onwards (Figure 2).

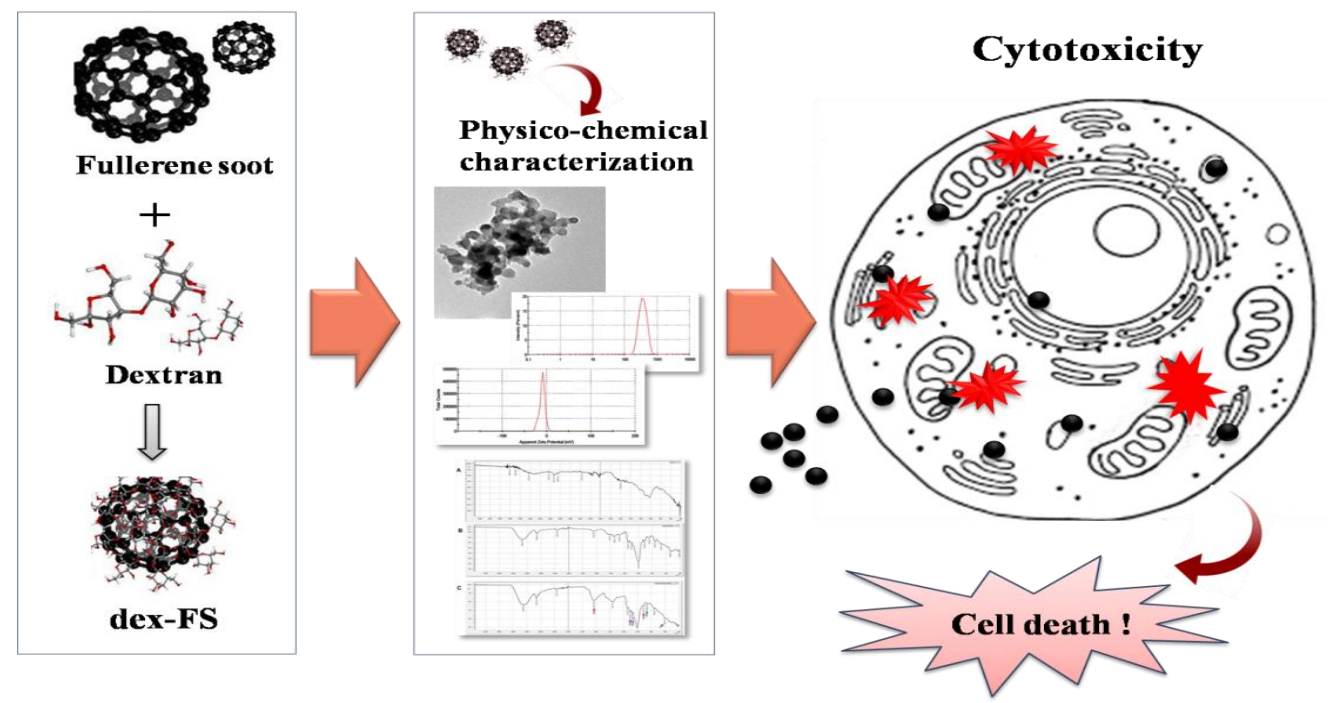

Figure 2. Overall impact of fullerene soot nanoparticles on glial cells.

Morphological perturbations were analyzed by both non-fluorescent (Coomassie Brilliant Blue) and fluorescent (Rhodmine Phalloidin) staining,both of which showed marked alterations within the cytoskeletal integrity of the cells exposed with higher concentrations 
$(160 \mu \mathrm{g} / \mathrm{ml})$ of fullerene soot nanoparticles. The organization of actin filaments was found to disturb at this dose. Sub-cellular organelles were evaluated for their functionalities, wherein lysosomal integrity was analyzed via Acridine orange staining. Consistent with the observation of morphology analysis, lysosomal stability of the cells was found to lose at higher dosage with a sharp shifting of absorbance spectra from red to green in the lysosomal compartment. A similar observation was obtained for JC1 staining, denoting the marked loss of mitochondrial membrane potential at higher tested concentrations.

Despite the information from certain literature saying free radical scavenging activity of fullerenes, the present study observed an increase in cellular oxidative stress as the dose of fullerene soot nanoparticles increased. The amount of ROS was markedly elevated as the dose increased. Calcein-AM/PI staining was performed for analysis of the live-dead pattern of fullerene soot nanoparticles exposed cells. Quantitative analysis of this further demonstrated marked cell death at higher concentrations. The influence of fullerene soot nanoparticle in nuclear premises of glial cells was analyzed using DAPI staining and DNA laddering assay via gel electrophoresis. Surprisingly, fullerene soot nanoparticles did not induce any nuclear toxicity as it failed to cause any laddering of DNA strands except some minute level of chromatin condensation. Any bands representing broken DNA were not observed in the gel, suggesting a non-genotoxic response. An illustration representing the overall impacts of fullerene soot nanoparticles in C6 cells if given in (Figure 3).

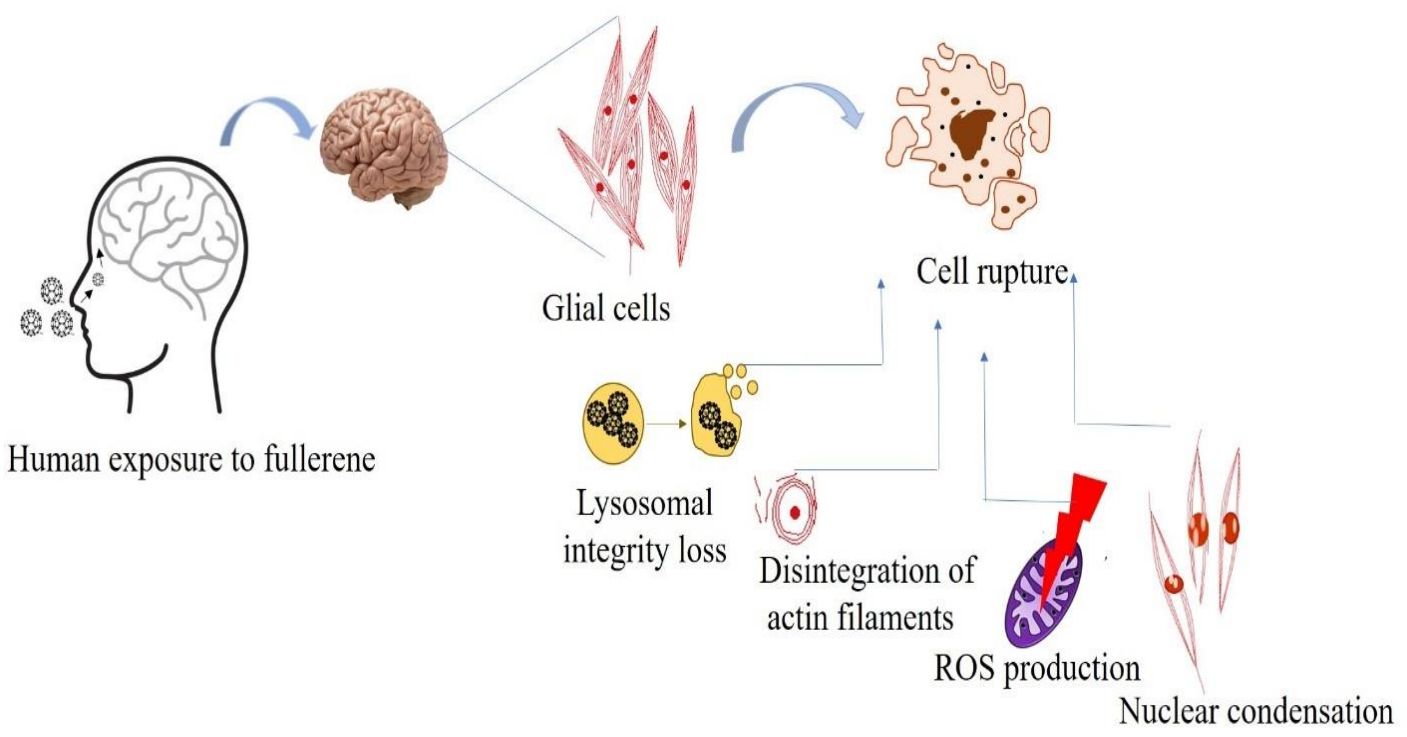

Figure 3. Chain of events on exposure to functionalized soot.

\section{Conclusions}

In a nutshell, that fullerene soot nanoparticles impose marked toxic responses in the glial cell community, thereby compromising the neuronal immune barrier. Also, it provides a cautious piece of information for having proper safety measures during exposure with soot sources like vehicle exhausts. The review also reminds the vital urge to consider the unintentional fullerene exposure from sources such as automobile/industrial exhaust, fuel combustion, or burning with almost seriousness since it could potentially cause a threat to neuronal cells and brain health. 


\section{Funding}

PVM thank Department of Science and Technology, Govt. of India, New Delhi for financial support (DST/TDT/DDP-04/2018(G)

\section{Acknowledgments}

The authors wish to express their thanks to the Director and Head, Biomedical Technology Wing, Sree Chitra Tirunal Institute for Medical Sciences and Technology (Govt. of India), Trivandrum, Kerala, India for their support and for providing the infrastructure to carry out this work.

\section{Conflicts of Interest}

The authors declare no conflict of interest.

\section{References}

1. De Nadaï, C.; Mirone, A.; Dhesi, S.S.; Bencok, P.; Brookes, N.B.; Marenne, I.; Rudolf, P.; Tagmatarchis, N.; Shinohara, H.; Dennis, T.J.S. Local magnetism in rare-earth metals encapsulated in fullerenes. Physical Review B 2004, 69, https://doi.org/10.1103/PhysRevB.69.184421.

2. Singh, S. Emerging Trends in Nanotechnology: Nanozymes, Imaging Probes and Biosensors and Nanocarriers. Current drug metabolism, 2019, 20(6):414-41, https://doi.org/10.1007/978-981-15-14906_8.

3. Pimpin, A.; Srituravanich, W.J.E.J. Review on micro-and nanolithography techniques and their applications. 2012, 16, 37-56,https://doi.org/10.4186/ej.2012.16.1.37.

4. Gupta, V.; Probst, P.T.; Goßler, F.R.; Steiner, A.M.; Schubert, J.; Brasse, Y.; König, T.A.; Fery, A. Mechanotunable surface lattice resonances in the visible optical range by soft lithography templates and directed self-assembly. ACS applied materials \& interfaces, 2019, 11, 28189-28196, https://doi.org/10.1021/acsami.9b08871.

5. Iavicoli, I.; Leso, V.; Ricciardi, W.; Hodson, L.L.; Hoover, M.D. Opportunities and challenges of nanotechnology in the green economy. Environmental Health, 2014, 13(1), 78, https://doi.org/10.1186/1476-069X-13-78.

6. Beumer, K. Nation-building and the governance of emerging technologies: the case of nanotechnology in India. NanoEthics, 2019, 13, 5-19, https://doi.org/10.1007/s11569-018-0327-8.

7. Krätschmer, W.; Lamb, L.D.; Fostiropoulos, K.; Huffman, D.R. Solid C60: a new form of carbon. Nature 1990, 347, 354-358,https://doi.org/10.1038/347354a0.

8. Rousseva, S.; Besten, H.D.; van Kooij, F.S.; Doting, E.L.; Doumon, N.Y.; Douvogianni, E.; Anton Koster, L.J.; Hummelen, J.C. Reaching a Double-Digit Dielectric Constant with Fullerene Derivatives. The Journal of Physical Chemistry C, 2020, 124(16), 8633-8638, https://doi.org/10.1021/acs.jpcc.0c01390.

9. Kroto, H.J.A.J.; Heath, J.R.;'O'Brien, S.C.; Curl, R.F.; Smalley, R.E. Long carbon chain molecules in circumstellar cells. The Astrophysical Journal, 1987, 314, https://doi.org/10.1086/165065.

10. Man, N.; Nagano, Y.; Kiyobayashi, T.; Sakiyama, M. Combustion Energy of Fullerene Soot. The Journal of Physical Chemistry 1995, 99, 2254-2255, https://doi.org/10.1021/j100008a004.

11. Athira, S.S.; Biby, T.E.; Mohanan, P.V. Effect of polymer functionalized fullerene soot on C6 glial cells. European Polymer Journal 2020, 127, https://doi.org/10.1016/j.eurpolymj.2020.109572.

12. Athira, S.S.; Biby, E.T.; Mohanan, P.V. Dextran stabilized fullerene soot induced toxicity on Alveolar epithelial cells (A549 cells). Environmental Research. 2020, 109716, https://doi.org/10.1016/j.envres.2020.109716.

13. Becker, L.; Bada, J.L.; Winans, R.E.; Hunt, J.E.; Bunch, T.E.; French, B.M. Fullerenes in the 1.85billion-year-old Sudbury impact structure. Science 1994, 265, 642-645, https://doi.org/10.1126/science.11536660.

14. Dugan, L.L.; Lovett, E.G.; Quick, K.L.; Lotharius, J.; Lin, T.T.; 'Malley' Malley O’Malley, K.L. Fullerene-based antioxidants and neurodegenerative disorders. Parkinsonism \& Related Disorders 2001, 7, 243-246, https://doi.org/10.1016/S1353-8020(00)00064-X. 
15. Ashtami, J.; Anju, S.; Mohanan, P.V. Conformity of dextran-coated fullerene C70 with L929 fibroblast cells. Colloids and Surfaces B: Biointerfaces, 2019, 184, 110530 , https://doi.org/10.1016/j.colsurfb.2019.110530

16. Anju, S.; Ashtami, J.; Mohanan, P.V. Effect of Surface Modified Fullerene C70 on the ROS Production and Cellular Integrity Using Chinese Hamster Ovarian Cells. General Chemistry, 2019, https://doi.org/10.21127/yaoyigc20190022.

17. Biby, E.T.; Prajitha, N.; Rajeev, K.S.; Mohanan, P.V. Cytoskeletal synchronization of CHO cells with polymer functionalized fullerene C60. Biointerphases, 2019, 14(2), 021002 , https://doi.org/10.1116/1.5084002

18. Biby, T.E.; Prajitha, N.; Ashtami, J.; Sakthikumar, D.; Maekawa, T.; Mohanan, P.V. Toxicity of dextran stabilized fullerene C60 against C6 Glial cells. Brain Research Bulletin, 2020, 155,191-201, https://doi.org/10.1016/j.brainresbull.2019.11.014.

19. Tykhomyrov, A.A.; Nedzvetsky, V.S.; Klochkov, V.K.; Andrievsky, G.V. Nanostructures of hydrated $\mathrm{C} 60$ fullerene $(\mathrm{C} 60 \mathrm{HyFn})$ protect rat brain against alcohol impact and attenuate behavioral impairments of alcoholized animals. Toxicology 2008, 246, 158-165, https://doi.org/10.1016/j.tox.2008.01.005.

20. Nakamura, E.; Isobe, H. Functionalized Fullerenes in Water. The First 10 Years of Their Chemistry, Biology, and Nanoscience. Accounts of Chemical Research 2003, 36, 807-815, https://doi.org/10.1021/ar030027y.

21. Baldrighi, M.; Trusel, M.; Tonini, R.; Giordani, S. Carbon Nanomaterials Interfacing with Neurons: An In vivo Perspective. 2016, 10, https://doi.org/10.3389/fnins.2016.00250.

22. Isakovic, A.; Markovic, Z.; Todorovic-Markovic, B.; Nikolic, N.; Vranjes-Djuric, S.; Mirkovic, M.; Dramicanin, M.; Harhaji, L.; Raicevic, N.; Nikolic, Z.; Trajkovic, V. Distinct Cytotoxic Mechanisms of Pristine versus Hydroxylated Fullerene. Toxicological Sciences 2006, 91, 173183,https://doi.org/10.1093/toxsci/kfj127.

23. Sayes, C.M.; Gobin, A.M.; Ausman, K.D.; Mendez, J.; West, J.L.; Colvin, V.L. Nano-C60 cytotoxicity is due to lipid peroxidation. Biomaterials 2005, 26, 7587-7595, https://doi.org/10.1016/j.biomaterials.2005.05.027.

24. Shanbogh, P.P.; Sundaram, N.G. Fullerenes revisited. Resonance 2015, 20, 123-135, https://doi.org/10.1007/s12045-015-0160-0. 